\title{
ALGUMAS CONSIDERAÇÕES COM REFERÊNCIA ÀS FORMAS DE REPRESENTAÇÃO DA TERRA ATRAVÉS DE COORDENADAS UTM
}

\author{
Elsbeth Léia Spode Becker e Edson Luis Piroli \\ Mestrandos em Sensoriamento Remoto - DER - CCR \\ Mario Luiz Trevisan \\ Departamento de Expressão Gráfica - CT \\ Roberto Cassol \\ Departamento de Geociências - CCNE \\ UFSM - Santa Maria, RS
}

\section{RESUMO}

A elaboração de mapas é uma atividade tão antiga que se confunde com a própria história da humanidade. Isso mostra a importância que o mapa sempre teve para o homem. Objetivou-se apresentar de forma suscinta algumas considerações acerca da Projecão Universal de Mercator como forma de representação da superfície curva da Terra sobre um plano.

Neste artigo fez-se um maior detalhamento da projeção Universal Transversa de Mercator - UTM, projeção esta recomendada, em 1951, pela Associação Geodésica Internacional para uso no mundo inteiro como uma forma para a uniformização cartográfica internacional. No Brasil, o sistema UTM passou a ser adotado em 1958, pela Diretoria de Serviço Geográfico do Exército (DSG). 


\section{ABSTRACT}

The elaboration of maps is such an old activity that made a mistakes with the humanity's own history. This shows the importance that the map allways had for the man.It was objectified to present in summarized form some considerations concerning as form of representation of the curved surface of the Earth on a plan.

This article made a larger detail of the Universal Transverse of Mercator - UTM projection. Projection this, recommended, in 1951, for the International Geodesic Association for use in the whole world as a form for the international cartographic standard, in big scale. In Brazil, the UTM system became adopted in 1955, for the Management of Geographical Service of the Army (DSG).

\section{I - INTRODUÇÃO}

Desde a antigüidade o homem tem buscado conhecer sua localização na Terra. Vê-se acompanhado das perguntas: Onde? O que existe neste lugar? Nos relatos da História percebe-se a constante busca da localização e, também, a representação, com perfeição, da superfície terrestre sobre uma superfície plana. Porém, a superfície da Terra apenas será verdadeiramente representada, sem distorção, sobre um globo de igual forma que ela. Para representar a Terra sobre uma superfície plana, nos sistemas desenvolvidos, sempre houve distorções, que devem ser minimizadas pela correta seleção da projeção.

Projeção é um traçado sistemático de linhas numa superfície, denominado grade, destinado à representação de paralelos de latitude e meridianos de longitude da Terra (OLIVEIRA, 1988).

O modelo de grade depende da posição do ponto de projeção e da posição do ponto do mapa. A superfície sobre a qual a projeção é feita 
pode ser um plano, um cone ou um cilindro. Uma vez que a grade é desenhada, características podem ser plotadas em suas corretas posições com referências aos meridianos e paralelos.

Em 1569, Mercator elaborou um mapa-múndi, em projeção cilíndrica isógena, e descreveu seus princípios e propriedades sobre o próprio mapa (OLIVEIRA, 1988).

Em 1951, a projeção Mercator (Universal Transversa de Mercator - UTM) foi adotada pela Associação Geodésica Internacional para uso no mundo inteiro para uniformização da cartografia internacional (OLIVEIRA, 1988).

Neste sistema, a Terra, representada por um elipsóide de revolução, foi dividida em sessenta fusos de $6^{\circ}$ de longitude, numerados de 1 a 60 , com origem no antimeridiano de Greenwich, em sentido anti-horário para um observador situado no polo norte.

\section{II - PROJEÇÃO UNIVERSAL TRANSVERSA DE MERCATOR (UTM)}

Gerhard Kremer Mercator (1512-1594) foi o matemático e cartógrafo, autor da projeção que levou seu nome. É considerado o "pai da cartografia moderna".

Mercator elaborou um mapa-múndi no sistema de projeção cilíndrica isógena (a projeção dos elementos é feita a partir de um mesmo ponto) em 1569 e descreveu seus princípios e propriedades sobre o próprio mapa. Tornou-se a projeção cilíndrica mais conhecida devido a sua grande utilidade para a navegação, sendo uma projeção onde os pontos tem a propriedade da conformidade (conservação da forma para uma área não muito extensa). Os meridianos e paralelos se interceptam sob ângulos retos (OLIVEIRA, 1988). 
Essa projeção não é apropriada para mapear as regiões dos pólos e zonas próximas a eles porque seria praticamente impossível projetálas sobre o cilindro uma vez que as linhas projetantes estariam cada vez mais beirando o paralelismo com seu eixo.

Desta forma, o cilindro é tangente à esfera representativa da Terra e seus eixos são coincidentes, isto é, o eixo de rotação da esfera com o eixo do cilindro (Figuras 1 e 2.a)

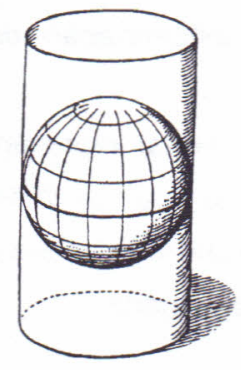

Figura 1 - Posicionamento relativo do planeta Terra e do cilindro utilizado para a projeção Mercator

Fonte: OLIVEIRA (1987)

Compilação: TREVISAN, M.L.

Uma variante da projeção de Mercator foi idealizada por Gauss, conservando a tangência do cilindro, porém com seu eixo formando um ângulo de $90^{\circ} \mathrm{com}$ o eixo do modelo, sendo, portanto, o eixo do cilindro transversal ao eixo de rotação do modelo (OLIVEIRA, 1988).

Transformando-se o cilindro tangente em secante pela redução de seu raio (Figura 2.b) e com a rotação de $90^{\circ}$ no eixo do cilíndro, este passa a cortar o elipsóide ao longo de dois meridianos eqüidistantes de um meridiano central (Figura 2.c) tem-se o princípio da projeção cartográfica denominada Universal Transversa de Mercator ou UTM (Figura 2.d). 

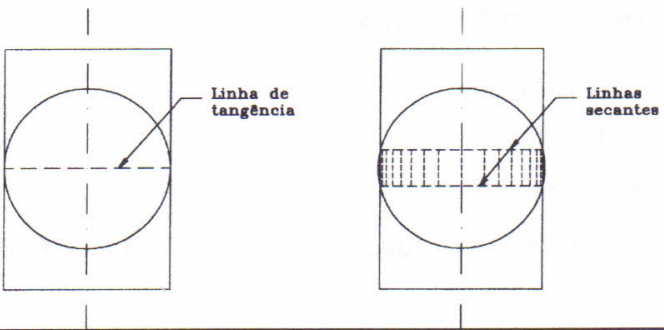

a) Esfera tangente ao cilindro

b) Cilindro secante a esfera

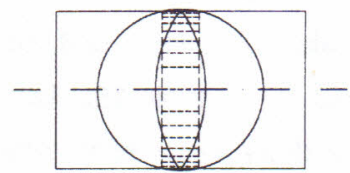

c) Rotação de $90^{\circ}$ no eixo do cilindro

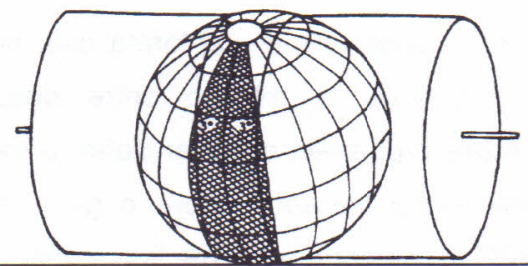

d) Cilíndro secante ao elipsóide terrestre

Figura 2 - Formação da projeção UTM

Fonte: AGUIRRE (1997) - adaptado

Diagramação: TREVISAN, M. L. 


\section{CARACTERÍSTICAS DO SISTEMA UTM}

- Coordenadas planas;

- Projeção cilíndrica;

- Projeção conforme;

- Divide toda a Terra em fusos de 6º, limitados por meridianos múltiplos de seis.

O fator de escala do meridiano central de cada fuso é 0,9996. Isto ocasiona um fator de escala $(\mathrm{K})$ de valor unitário à altura de duas linhas meridianas, distanciadas mais ou menos $180 \mathrm{~km}$ a leste e a oeste do meridiano central e ainda gera duas linhas sem deformação linear $(K=1)$ em cada fuso, ao invés de uma (GEMAEL, 1980).

Esta projeção tem os paralelos horizontais e os meridianos verticais. Os meridianos estão locados de tal forma que o espaçamento entre eles é verdadeiro no Equador (naturalmente considerando a escala).

A projeção de Mercator, portanto, apresenta uma grande deformação na região dos pólos, sendo verdadeira a grandeza mostrada no Equador.

Os paralelos são espaçados de tal forma que, numa zona de dimensões relativamente pequenas, a relação entre duas distâncias, tomadas respectivamente sobre o paralelo e o meridiano, é igual à relação entre os comprimentos homólogos tomados sobre o globo terrestre. Por exemplo, na latitude de $60^{\circ}$, o comprimento medido sobre o paralelo é deformado para mais, e é duas vezes maior do que um comprimento medido sobre o Equador, que se apresentará em sua verdadeira grandeza, considerando-se a escala.

Mas se os meridianos guardam o mesmo espaçamento em todas as latitudes, disto resulta que as dimensões do mapa serão exageradas, chegando a deformação a $100 \%$ na latitude de $60 \%$. Na latitude de $80^{\circ}$ esta ampliação de dimensões chega a ser de seis vezes a do 
Equador. Por isso, é evidente que nesta projeção não se pode representar os pólos, pois os meridianos, sendo paralelos entre si, só se encontrarão no infinito.

A projeção cilíndrica de Mercator não é uma projeção propriamente dita, mas sim, uma modificação desta classe de representações. Configura-se como um sistema da projeção transversa de Mercator (conforme de Gauss). Este sistema surgiu em 1947 para determinar as coordenadas retangulares nas cartas militares, em escala grande, de todo o mundo, por recomendação da União Geodésica Internacional para a uniformização cartográfica. A projeção adotada mundialmente é a estereográfica polar universal (GEMAEL, 1980).

O Brasil, através da Diretoria do Serviço Geográfico (DSG), passou a utilizar esse sistema a partir de 1958, transformada as coordenadas plano-retangulares de Gauss para o sistema UTM.

\section{ORIGEM DO ÍNDICE DE NOMENCLATURA DE CARTAS}

O sistema UTM estabelece que a Terra seja dividida em sessenta fusos de seis graus de longitude, os quais têm início no antimeridiano de Greenwich $\left(180^{\circ}\right)$, e que seguem de oeste para leste a partir deste fuso, até o fechamento neste mesmo ponto de origem. Quanto à extensão em latitude, os fusos se originam no paralelo de $80^{\circ} \mathrm{S}$ até $\mathrm{O}$ paralelo $80^{\circ} \mathrm{N}$. Os fusos são decorrentes da necessidade de se reduzirem as deformações (CARVALHO, 1988).

Assim, o globo terrestre foi dividido em faixas de $6^{\circ}$ na direção da longitude, sendo as faixas numeradas de 1 a 60 de oeste para leste, iniciando-se a numeração no antimeridiano de Greenwich.

Se em relação à longitude os fusos são de número 60 , no que toca à latitude a divisão consiste em zonas de quatro graus (isto está vinculado ao tamanho da carta de 1:1.000.000, e não à projeção). 
A Figura 3 demonstra quatro quadrículas localizadas na região Sul do Brasil. Nesta figura, duas quadrículas apresentam o meridiano central de $51^{\circ}$ e os dois meridianos laterais de $48^{\circ}$ e $54^{\circ}$ respectivamente. As duas outras apresentam o meridiano central de $57^{\circ}$ e os dois laterais de $54^{\circ}$ e $60^{\circ}$ respectivamente. Quanto aos limites em latitude, tem-se, para as quadrículas, os paralelos de $24^{\circ}, 28^{\circ}$ e $32^{\circ}$.

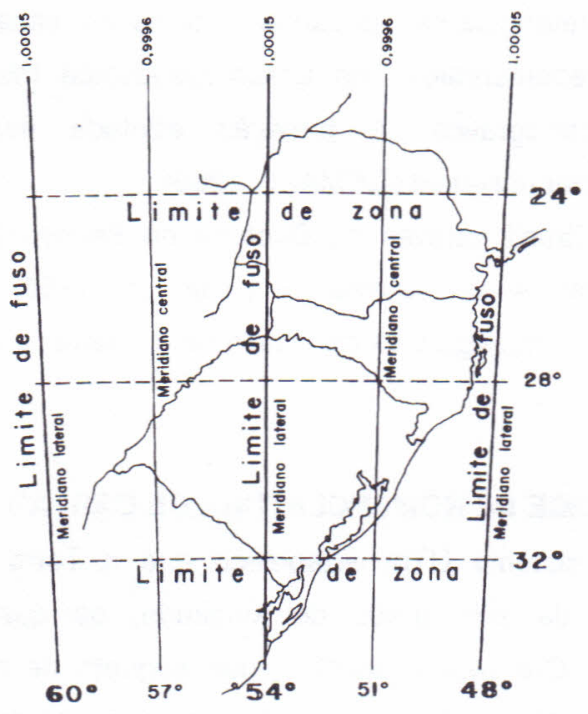

Figura 3 - Limites de quadrículas em relação a fusos e zonas na Região Sul do Brasil. Diagramação: TREVISAN, M. L.

Pode-se observar que o estado do Rio Grande do Sul situa-se entre dois fusos, enquanto Santa Catarina insere-se em apenas um fuso.

As fusos correspondentes ao território brasileiro vão de 18 a 25, sendo as do estado do Rio Grande do Sul de 21 e 22, conforme se observa na Figura 4. 


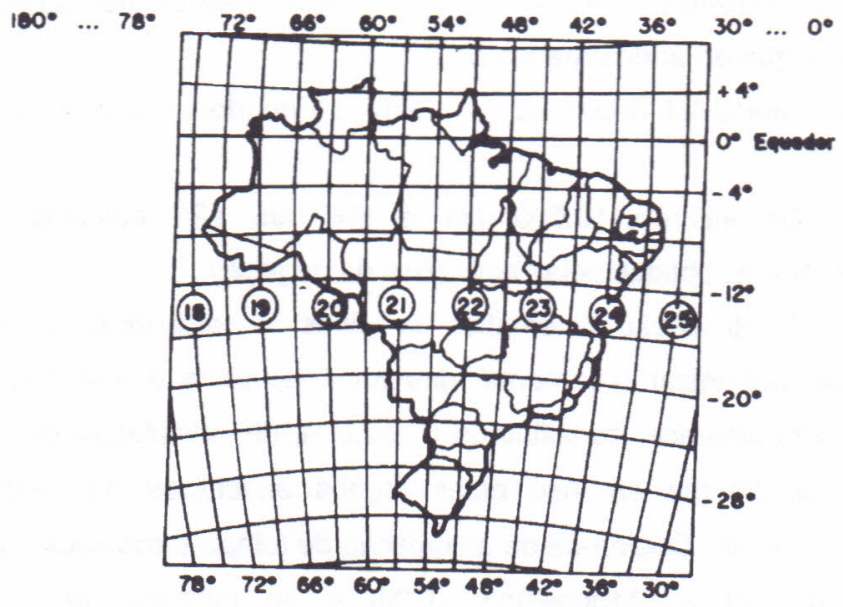

Figura 4 - Fusos UTM para o Brasil

Fonte: AGUIRRE (1997) - adaptado

Diagramação: TREVISAN, M. L.

\section{ARTICULAÇÃO SISTEMÁTICA DAS FOLHAS DE CARTA}

Os fusos de 6 을 longitude são divididos na latitude de quatro em quatro graus, iniciando no Equador, recebendo cada quadrícula a designação de uma letra do alfabeto que será antecedida pela letra "S" ou "N" conforme a posição Sul ou Norte do Equador (AGUIRRE, 1997).

As coordenadas de origem de uma quadrícula são:

a) Hemisfério sul

Na direção leste-oeste: $500 \mathrm{~km}(500.000 \mathrm{~m})$ no fuso central, reduzindo no sentido oeste e aumentando para leste;

Na direção norte-sul: $10.000 \mathrm{~km}(10.000 .000 \mathrm{~m})$ no Equador, reduzindo no sentido norte para o sul. 
b) Hemisfério norte

$\mathrm{Na}$ direção leste-oeste: $500 \mathrm{~km}(500.000 \mathrm{~m})$ no fuso central, diminuindo para o oeste e aumentando para leste;

$\mathrm{Na}$ direção norte-sul: origina-se em $0 \mathrm{~km}$ no Equador no sentido sul para norte.

Os valores $10.000 \mathrm{~km}$ e $500 \mathrm{~km}$ são adicionados às coordenadas $\mathrm{N}$ e E, obtidas pelas equações da projeção.

A articulação sistemática de folhas de carta foi criada com a finalidade de padronizar o tamanho das folha de carta e sua respectiva designação alfanumérica, constituindo o Sistema de Articulação de Folhas de Cartas, atualmente em uso pelos órgãos envolvidos na cartografia sistemática do Brasil. Origina-se da articulação de folhas estabelecida para a carta Internacional ao Milionésimo (CIM) e se estende até a carta Topográfica na escala 1:25.000. O decreto-lei 243/67 de 28 de fevereiro de 1967 e a portaria 124/EME de 28 de setembro de 1971 fixam as normas para esta articulação (GAMEL , 19800.

Observa-se na Figura 5 a conformação do Índice de Nomenclatura das CIM para o Brasil, tomando como exemplo a quadrícula $\mathrm{SH}-22$, onde se refere a cidade de Porto Alegre.

\section{ARTICULAÇÃO DA CIM À CARTA 1:25.000}

A quadrícula básica corresponderá à da $\mathrm{CIM}$, tendo os mesmos meridianos centrais do Sistema UTM. Utilizando-se o exemplo da Figura 5, tomou-se o marco zero de Porto Alegre de coordenadas:

Latitude $=-30^{\circ} 02^{\prime} 00^{\prime \prime}$ Sul

Longitude $=51^{\circ} 13^{\prime} 00^{\prime \prime}$ Oeste 


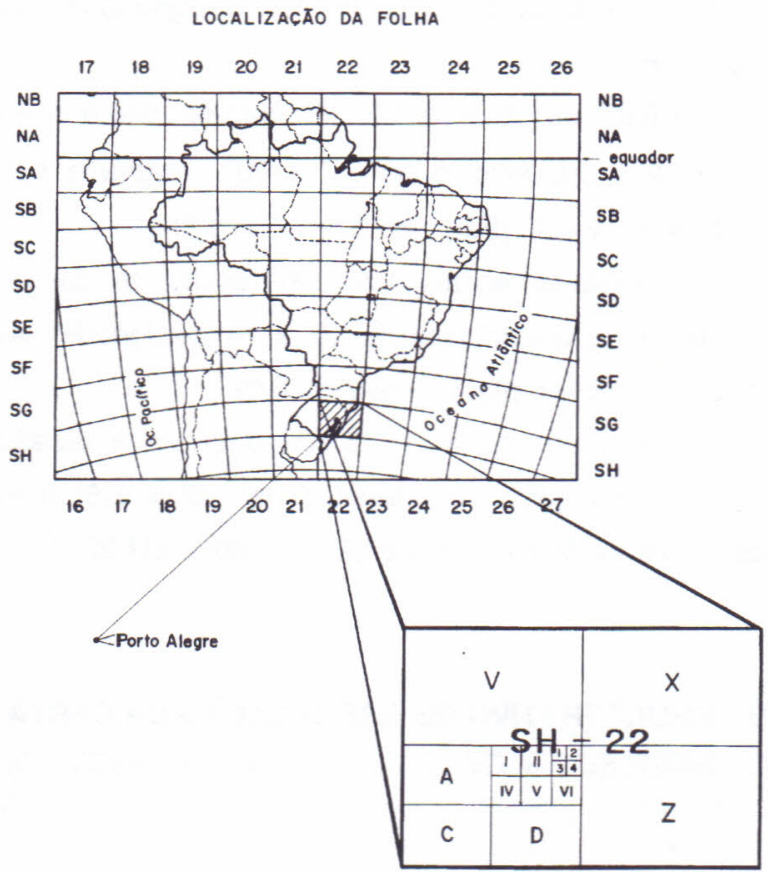

Figura 5 - Conformação do Índice de Nomenclatura das CIM para o Brasil Diagramação: TREVISAN: M. L.

O resultado é a quadrícula $\mathrm{SH}-22$. A letra $\mathrm{S}$ é devido à localização no Hemisfério Sul e a letra $\mathrm{H}$ é devido a sequência alfabética iniciada no Equador. A partir daí faz-se a subdivisão sistemática até a carta na escala 1:25.000, como descrito a seguir:

A folha de escala 1:500.000 resulta da divisão da folha da quadrícula básica em quatro quadrículas de $2^{\circ} \times 3^{\circ}$ designadas pelas letras V, X, Y e Z (Exemplo: SH-22-Y); 
A folha de escala 1:250.000 equivale à divisão da folha de 1:500.000 em quatro quadrículas de $1^{\circ} \times 1,5^{\circ}$ designadas pelas letras $A, B, C$ e D (Exemplo: SH-22-Y-B);

A folha de escala 1:100.000 corresponde à divisão da folha de 1:250.000 em seis quadrículas de 30' x 30' designada pelos algarismos romanos I, II, III, IV, V e VI (Exemplo: SH-22-Y-B-III);

A folha de escala 1:50.000 resulta da divisão da folha de 1:100.000 em quatro quadrículas de $15^{\prime} \times 15^{\prime}$ designada pelos algarismos arábicos 1, 2, 3 e 4 (Exemplo: SH-22-Y-B-III-2);

A folha de escala 1:25.000 equivale à divisão da folha de escala 1:50.000 em quatro quadrículas de 7,5' x 7,5' designadas pelos quadrantes colaterais NO, NE, SO e SE (Exemplo: SH-22-Y-B-III-2-NO).

\section{QUADRO DEMONSTRATIVO DE ARTICULAÇÃO DA CARTA BÁSICA}

\begin{tabular}{lllll}
$\begin{array}{l}\text { ESCALA DA } \\
\text { FOLHA }\end{array}$ & $\begin{array}{l}\text { FORMATO DA } \\
\text { FOLHA }\left({ }^{\circ} \cdot{ }^{\prime \prime}\right)\end{array}$ & $\begin{array}{l}\text { AREA DO TERRENO } \\
\text { ABRANGIDA }(\mathrm{Km})\end{array}$ & $\begin{array}{l}\text { DIMENSÖES DA FOLHA } \\
(\mathrm{cm})\end{array}$ & $\begin{array}{l}\text { ARTICULAÇAO DA } \\
\text { FOLHA }\end{array}$ \\
\hdashline $1: 1.000 .000$ & $4^{\circ} \times 6^{\circ}$ & $444,48 \times 666,72$ & $44,44 \times 66,67$ & SH-22 \\
$1: 500.000$ & $2^{\circ} \times 3^{\circ}$ & $222.24 \times 333,36$ & $44,44 \times 66,67$ & SH-22-Y \\
$1: 250.000$ & $1^{\circ} \times 1,5^{\circ}$ & $111,12 \times 166,68$ & $55,56 \times 55,56$ & SH-22-Y-B \\
$1: 100.000$ & $30^{\prime} \times 30^{\prime}$ & $55,56 \times 55,56$ & $55,56 \times 55,56$ & SH-22-Y-B-III \\
$1: 50.000$ & $15^{\prime} \times 15^{\prime}$ & $27,78 \times 27,78$ & $55,56 \times 55,56$ & SH-22-Y-B-III-2 \\
$1: 25.000$ & $7,5^{\prime} \times 7,5^{\prime}$ & $13,89 \times 13,89$ & $55,56 \times 55,56$ & SH-22-Y-B-III-2-NO
\end{tabular}

Conforme mostra o quadro acima, com este sistema obtém-se a padronização, tanto no tamanho quanto na designação das folhas de cartas, representada na Figura 6.

Considerando-se os países com grandes dimensões, como a Rússia, a China, o Canadá, os Estados Unidos e o Brasil, percebe-se a grande importância e praticidade deste sistema. Para mapear totalmente o Brasil seriam necessárias aproximadamente 3.065 cartas de 1:100.000 ou 12.144 cartas de 1:50.000 ou, ainda, 48.576 cartas de 1:25.000. 
Escala

1:25.000

$1: 60.000$

1:100.000

$1: 250.000$

1:600.000

1:1.000.000
Folha

Articulação

SH-22-Y-B-III-2-NO

SH-22-Y-B-III-2

$15^{\prime} \times 15^{\prime}$

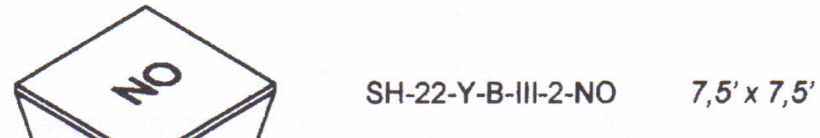

SH-22-Y-B-III

$30^{\prime} \times 30^{\prime}$

SH-22-Y-B

$1^{\circ} \times 1,5^{\circ}$

SH-22-Y

$2^{\circ} \times 3^{\circ}$

$\mathrm{SH}-22$

$4^{\circ} \times 6^{0}$

Figura 6 - Articulação das CIM

Diagramação: TREVISAN, M. L. 


\section{CONSIDERAÇÕES FINAIS:}

A Cartografia tem por finalidade básica a elaboração de cartas ou mapas, que são superfícies planas onde a Terra se acha total ou parcialmente representada (OLIVEIRA, 1987).

Embora o mapa e a carta tenham quase tudo em comum, sendo inclusive considerados sinônimos, no Brasil costuma-se diferenciá-los.

Emprega-se o termo mapa para as representações mais simples, generalizadas ou em escala muito pequena. Exemplos: mapa do Brasil (escala 1:5.000.000 ou menor), mapa da América do Sul e mapamúndi. A carta, sempre expressa curvas de nível, apresenta maior detalhamento, mais precisão, é representada em escala grande, e é limitada por coordenadas geográficas. Exemplos: cartas topográficas, cartas cadastrais ou urbanas (escalas de 1:500 a 1:2.000) e cartas de navegação marítima e aérea (cartas náuticas e cartas aeronáuticas) (OLIVEIRA, 1987).

$\mathrm{Na}$ atualidade, mapas, cartas e plantas são amplamente utilizados por geógrafos, professores, engenheiros, estudantes, militares e outros profissionais, além de turistas. Tem-se as mais diferentes representações, em escalas apropriadas, de todos os lugares da superfície terrestre e da Terra através do mapa-múndi.

O desenvolvimento da cartografia moderna decorreu principalmente das grandes navegações oceânicas (séculos XV e XVI) e em particular da contribuição dada pela Escola de Sagres (formação de pilotos e cartógrafos, aperfeiçoamento das caravelas, do astrolábio e das cartas de navegação). Entretanto, o impulso definitivo ao desenvolvimento da Cartografia deu-se a partir de 1569, com a criação da projeção cilíndrica de Mercator (OLIVEIRA, 1987).

Portanto, este sistema serve para simplificar a localização de um ponto na superfície terrestre, visando também auxiliar o uso de processamento automatizado de referenciamento por computador. 


\section{BIBLIOGRAFIA}

AGUIRRE, A. J. Transformação de Coordenadas Aplicáveis em Topografia. In: Educação para Crescer. Cap. II. Porto Alegre/RS: Secretaria de Educação/Governo do RS, 1993. 98 p.

Curso de GPS Geodésico e Topográfico de Santa Maria - RS. Departamento de Engenharia Rural. CCR - UFSM. 1997. 23p.

CARVALHO, M. C. Cartografia. Básica. Série. Florianópolis. SC., Editora UFSC.

GEMAEL, C. Introdução à Astronomia Esférica. Curitiba/PR: Curso de Pós-Graduação em Ciências Geodésicas, 1980. 108 p. (Caderno Didático).

OLIVEIRA, C. Dicionário Cartográfico. IBGE, RJ, 1987.

Curso de Cartografia Moderna. IBGE, RJ, 1988. 